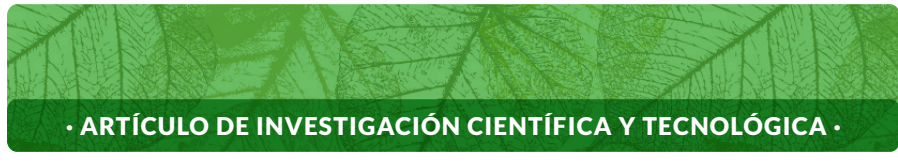

Vol. 19 No 2 • Julio - Diciembre 2021 · ISSN - 1692-3561 · ISSN-e 1909-9959 • https://doi.org/10.18684/bsaa.v19.n2.2021.1848

\title{
Degradación enzimática de mucílago de Coffea arábica L., para la producción de café suave lavado*
}

\section{Enzymatic mucilage degradation from Coffea arabica L., for washed coffee production}

PEÑUELA-MARTÍNEZ, AIDA-ESTHER'; TIBADUIZA-VIANCHÁ, CARLOS-ALFONSO'; MORCILLO, CAMILO-ANDRÉS'; RESTREPO-RIVERA, MARIA-VALENTINA ${ }^{9}$

Historial del Artículo

Recibido para evaluación: 9 de Febrero 2021.

Aprobado para publicación: 24 de Abril 2021.

* $\quad$ Proyecto de origen: "Evaluación del efecto de la reutilización de una pectina liasa en la eliminación de mucílago de café". Financiación: Federación Nacional de cafeteros de Colombia. Culminación: 6 de septiembre de 2020.

6 Centro Nacional de Investigaciones de Café (CENICAFÉ). Grupo de Investigación de Pos cosecha. Ph.D. Biotecnología. Manizales, Colombia. https://orcid.org/0000-0003-4454-9778

7 Centro Nacional de Investigaciones de Café (CENICAFÉ). Grupo de Investigación de Pos cosecha de Café. Ingeniero Agrícola, M.Sc. Manizales, Colombia. https://orcid.org/0000-0002-7053-0942

8 Centro Nacional de Investigaciones de Café (CENICAFÉ). Grupo de Investigación de Pos cosecha. Biólogo. Manizales, Colombia. https://orcid.org/0000-0002-1536-9914

9 Centro Nacional de Investigaciones de Café (CENICAFÉ). Grupo de Investigación de Pos cosecha. Estudiante Ingeniería de alimentos. Manizales, Colombia. https://orcid.org/0000-0002-6845-4215

Correspondencia: AidaE.Penuela@cafedecolombia.com

Cómo citar este artículo: PEÑUELA-MARTÍNEZ, AIDA-ESTHER; TIBADUIZA-VIANCHÁ, CARLOS-ALFONSO; MORCILLO, CAMILO-ANDRÉS; RESTREPO-RIVERA, MARIA-VALENTINA. Degradación enzimática de mucílago de Coffea arábica L., para la producción de café suave lavado. Biotecnología en el sector agropecuario y agroindustrial, v. 19, n. 2, 2021, p. 170-183. Doi: https:// doi.org/10.18684/bsaa.v19.n2.2021.1848 


\section{RESUMEN}

La remoción del mucílago de café requiere de la degradación de la pectina durante la fermentación, necesaria para la obtención del café suave lavado. Esta etapa representa gran parte del tiempo de procesamiento, por lo que el uso de pectinasas es importante para acelerar la remoción de mucílago y lograr la eficiencia en esta operación. Actualmente, se utiliza una pectina liasa, sin embargo, se desconoce si su aplicación en concentraciones inferiores a las recomendadas y la recirculación de los fluidos resultantes para nuevas tandas de café, generan efectos sobre el desarrollo del proceso y la calidad de la bebida. Para determinar este efecto se utilizó un Diseño de Bloques al Azar en arreglo factorial $2 \times 3+1$ con dos concentraciones de enzima, tres ciclos de aplicación, original y recirculación y un testigo, que fue la fermentación tradicional. Se realizó el Análisis de varianza y prueba de Tukey, cuando se encontró efecto significativo. Los procesos en las masas de café transcurrieron entre 22 y $27^{\circ} \mathrm{C}$, el pH entre 5,6 y 3,5. Los resultados indicaron diferencias en el tiempo de degradación, el cual se redujo respecto al testigo, entre 79 y $85 \%$ con el primer uso de la enzima y entre 22 y $23 \%$ para el uso de los primeros fluidos drenados obtenidos. La calidad del café no presentó diferencias significativas, con puntajes SCA entre 81,18 y 81,80 . Las características de $\mathrm{pH}$, viscosidad y volumen de los fluidos drenados que contenían la enzima variaron de acuerdo con la concentración y el tipo de aplicación, obteniendo mayor volumen y menor viscosidad y acidez para los resultantes de la aplicación inicial. El uso de esta pectinasa es una alternativa para degradar el mucílago de café, ya que no afecta la calidad y disminuye el tiempo de proceso independiente del ciclo de aplicación utilizado.

\section{ABSTRACT}

The coffee mucilage elimination requires the pectin degradation, often performed by natural fermentation, which is indeed an important stage to obtain washed coffees. Fermentation represents a large part of the wet coffee processing time, which causes a delay to obtaining the product, especially in the peak production seasons. Therefore, the use of pectinases is important to accelerate mucilage degradation and improve the efficiency in this stage. However, the effects by application in concentrations lower than those recommended and the recycling of the fluids obtained to new batches of coffee, are unknown in the coffee fermentation process and the quality of the beverage. To determine this effect, a Random Block experimental Design was conducted in a $2 \times 3+1$ factorial arrangement, with two levels of enzyme concentrations and three application cycles, original enzyme and recirculation. The control treatment was the traditional fermentation. Anova and Tukey tests were performed when significant effect was found. Temperature in the coffee masses of the treatments, ranged between 22 and $27^{\circ} \mathrm{C}$ and the $\mathrm{pH}$ between 5,6 and 3,5. The results indicated differences in the degradation time, which was reduced, between 79 and $85 \%$ in the first use, and between 22 and 23 $\%$ in the first re-use, compared to the control. The coffee cup quality did not show significant differences, with SCA scores varying between 81,18 and 81,80 . Characteristics such as $\mathrm{pH}$, viscosity and volume of the drained fluids varied according to the concentration and number of recirculations of the enzyme, obtaining

\section{PALABRAS CLAVE:}

Café; Mucílago; Pectina; Degradación enzimática; Pectinasa; Tiempo de remoción; Fermentación natural; Fluidos drenados; Viscosidad; Calidad sensorial.

\section{KEYWORDS:}

Coffee; Mucilage; Pectin; Enzymatic Degradation; Pectinase; Removal Time; Natural Fermentation; Drained Fluids; Viscosity; Sensory Quality. 
a higher volume as well as lower viscosity and acidity for those resulting from the first application. The use of this pectinase is an alternative to accelerate degradation of coffee mucilage, since its use does not affect the quality.

\section{INTRODUCCIÓN}

En el proceso de beneficio húmedo de café, la fermentación es una etapa necesaria para eliminar el mucílago y facilitar su remoción mediante el lavado, de esta forma obtener el café suave lavado que caracteriza el café colombiano en el mercado internacional. En la fermentación del café ocurren diferentes reacciones bioquímicas generadas por las enzimas que son producidas por los microorganismos propios del fruto que permiten la transformación del mucílago, el cual representa entre el 15,5 y 22 \% del peso fresco del fruto (Menchú, 2019). La fermentación puede tomar más de 16 horas la mayoría de las veces, dependiendo de factores como el clima, la época de cosecha, la madurez de los frutos, entre otros, por lo que el tiempo total del proceso de beneficio húmedo se debe en gran medida al tiempo que toma la fermentación (Sanz et al., 2017).

La materia seca del mucílago está compuesta principalmente por carbohidratos (81,4\%) de los cuales el $48 \%$ son azúcares reductores, 30 \% son azúcares no reductores, 15 \% sustancias pécticas y 7 \% fibra. A su vez, la pectina del mucílago de café se caracteriza por tener ácido galacturónico con alto grado de metilación y niveles moderados de acetilación (Avallone et al., 2000). Naturalmente el mucílago es degradado por diferentes tipos de pectinasas, producidas por los microorganismos que participan en la fermentación, estás enzimas catalizan la hidrólisis de la pectina, que es uno de los principales polisacáridos estructurales de las células de las plantas (Avallone et al., 2000; Kazemi et al.,2019; Asgari et al.,2020), entre ellas el mucílago de café.

El uso de pectinasas en la industria de alimentos y bebidas representa cerca del $30 \%$ del mercado total de enzimas, que está alrededor de 100 millones de USD al año, de éstas, la mayoría son derivadas de hongos filamentosos, especialmente del género Aspergillus (Zeuner et al., 2020) por lo que han sido el foco de gran cantidad de investigaciones en la última década (John et al., 2020).

La eliminación de mucílago por vía enzimática es uno de los usos industriales y de aplicaciones biotecnológicas con potencial identificado recientemente (Ramdas-Shet et al., 2018). Trabajos previos de evaluación de una pectinasa comercial despolimerizante de tipo pectina liasa, endopolimetilgalacturonato liasa (E.C 4.2.2.1.0.) proveniente de Aspergillus niger, cuya actividad máxima sobre mucílago de café fue observada a pH 5,0 y una temperatura de $55^{\circ} \mathrm{C}$, mostró una reducción en el tiempo de remoción hasta del $90 \%$, sin afectar la calidad en taza, respecto al proceso tradicional, cuando se utilizó en concentraciones entre 100 y $400 \mathrm{mg} \cdot \mathrm{kg}^{-1} \mathrm{de}_{\mathrm{café}}$ despulpado (Peñuela-Martínez et al., 2010). Este tipo de enzima ejerce mayor velocidad de reacción sobre pectina altamente metilada y no esterificada (Xu et al., 2015; He et al., 2018; Zeuner et al., 2020), cuyas reacciones se caracterizan por generar pérdida de viscosidad y aumento de sólidos solubles totales (Kc et al., 2020).

En Colombia, en las fincas cafeteras que utilizan fermentación, el dimensionamiento y diseño de las plantas de proceso se realiza considerando principalmente la cantidad máxima de frutos de café que pueden ser acopiados en un solo día. La capacidad de los tanques de almacenamiento de café despulpado para la fermentación es un aspecto limitante, debido a que representa uno de los más altos costos en la inversión inicial y al espacio que demanda su instalación, su utilización se limita a la semana de mayor producción del año, lo que representa subutilización de la infraestructura para el proceso de café la mayor parte del tiempo (Tibaduiza et al., 2018).

La reducción en el tiempo de remoción de mucílago del café con la adición de esta pectina liasa permite duplicar o hasta triplicar la capacidad instalada de los tanques de fermentación especialmente en los días de mayor ingreso de café, a un bajo costo y sin afectar la calidad final del producto (Peñuela et al., 2010). Esta pectinasa está siendo usada con mayor frecuencia por los caficultores, sobre todo en épocas de plena cosecha, para mayor aprovechamiento de la infraestructura de procesamiento de café y conservación de la calidad del café de Colombia. 
Por otra parte, los mecanismos de acción de las enzimas, indican que una vez agotado el sustrato y si existen las condiciones para que continúen con la actividad remanente, pueden actuar sobre sustrato nuevo. Por lo que uno de los métodos más simples de recuperación de enzimas es la recirculación, que se basa en la reabsorción de las mismas en el sobrenadante de la reacción sobre un sustrato fresco (Yuan et al., 2018), esta técnica es usada por ejemplo para la obtención de bioetanol a partir de residuos lignocelulósicos, dado el alto costo de las enzimas necesarias para la hidrólisis (JØrgensen y Pinelo, 2017; Xue et al., 2012; Salvador et al., 2018; Yuan et al., 2018).

En el caso del café, la pectina liasa se requiere para desagregar la estructura de la pectina, proceso que comienza rápidamente después de su aplicación, generando un fluido que se separa de la masa de café y que drena a través de los granos, al inferior del tanque de fermentación. Estos fluidos contienen parte de la enzima aplicada, por lo que ha surgido la práctica de recolectarlos y recircularlos sobre una nueva tanda de café despulpado, con el objetivo de reducir el tiempo de remoción de mucílago y aprovechar la capacidad de degradación de la enzima contenida inicialmente, también se ha reducido la cantidad de enzima que se debe aplicar, para disminuir el costo de adquisición del producto comercial. Pese a que es una práctica utilizada en otros procesos industriales en una mayor complejidad (JØrgensen y Pinelo, 2017), no se conoce su efectividad en la degradación de mucílago de café o su impacto sobre la calidad final. El presente trabajo presenta los resultados de la evaluación del uso de una menor concentración de esta pectinasa, respecto a las evaluadas en estudios anteriores (Peñuela et al., 2010). Además, de la recirculación de los fluidos drenados del proceso sobre nuevas tandas de café y del impacto de esta práctica sobre la calidad final de la bebida, con el fin de generar una recomendación sobre el mejor uso de esta enzima, que no implique riesgo en el proceso o en la calidad del café colombiano.

\section{MÉTODO}

Esta investigación se realizó en un beneficiadero experimental, ubicado en Manizales Caldas, Colombia, a 1.310 m de altitud, con temperatura media anual de $21,2^{\circ} \mathrm{C}$ y humedad relativa del $78 \%$. Se utilizó café en variedades Castillo ${ }^{\circledR}$ General y Cenicafé $1 \circledR$, de manera independiente.

\section{Desarrollo experimental}

Se utilizó un Diseño de Bloques al Azar en arreglo factorial 2×3+1, siendo los factores la concentración de enzima (50 y $100 \mathrm{mg}_{\text {enzima }} \cdot \mathrm{kg}_{\text {cafédespulpado }}{ }^{-1}$ ) y el ciclo de uso de la enzima: la aplicación de enzima original y hasta dos recirculaciones de los fluidos drenados para degradación enzimática de nuevas tandas de café despulpado, con un testigo o control absoluto que fue la fermentación natural (sin aplicación de enzima), para un total de siete tratamientos (Cuadro 1). En total se realizaron 10 bloques, considerando como factor de bloqueo la calidad de la masa de café, la cual fue caracterizada por estados de madurez, tomando una muestra compuesta de $1 \mathrm{~kg}$, para determinar el porcentaje de frutos inmaduros, maduros y sobremaduros. La masa de café de cada bloque se dividió en siete partes iguales, que fueron asignadas aleatoriamente a los tratamientos. Las unidades de trabajo estuvieron conformadas por $40 \mathrm{~kg}$ de café despulpado. Una vez finalizada la degradación, cada unidad de trabajo se lavó separadamente con un equipo Ecomill ${ }^{\circledR}$ LH-300 y fue llevada a secado solar hasta alcanzar una humedad entre 10 y $12 \%$ en base húmeda (b.h).

Para obtener los primeros tratamientos (1 y 4), se despulparon $200 \mathrm{~kg}$ de frutos de café, se dividió en tres partes, dos para aplicar la enzima original en la concentración correspondiente y la otra para el testigo. 
Cuadro 1. Tratamientos evaluados.

\begin{tabular}{|c|l|c|c|}
\hline \multirow{2}{*}{ Tratamiento } & \multicolumn{1}{|c|}{ Descripción } & Ciclo & $\begin{array}{c}\text { Concentración de enzima } \\
\left(\mathbf{g}_{\text {enzima }} \cdot \mathbf{k g}_{\text {cafédespulpado }}{ }^{-1}\right)\end{array}$ \\
\hline 1 & Aplicación de la pectinasa original según concentración & 1 & 50 \\
\hline 2 & Primera recirculación de los fluidos drenados & 2 & 50 \\
\hline 3 & Segunda recirculación de los fluidos drenados & 3 & 50 \\
\hline 4 & Aplicación de la pectinasa original según concentración & 1 & 100 \\
\hline 5 & Primera recirculación de los fluidos drenados & 2 & 100 \\
\hline 6 & Segunda recirculación de los fluidos drenados & 3 & 100 \\
\hline 7 & Sin aplicación de pectinasa & Testigo & \\
\hline
\end{tabular}

El café despulpado de cada tratamiento fue depositado en los tanques de fermentación (Figura 1) y se aplicó la enzima en la concentración correspondiente asperjándola sobre el café despulpado. El café utilizado para las unidades de trabajo correspondientes a los tratamientos 2, 3, 5 y 6, fue conservado en un cuarto refrigerado, con el fin de evitar degradación de mucílago. Cada unidad de trabajo fue retirada oportunamente, al momento de requerirse, para equilibrar la temperatura del fruto con el ambiente previo al despulpado.

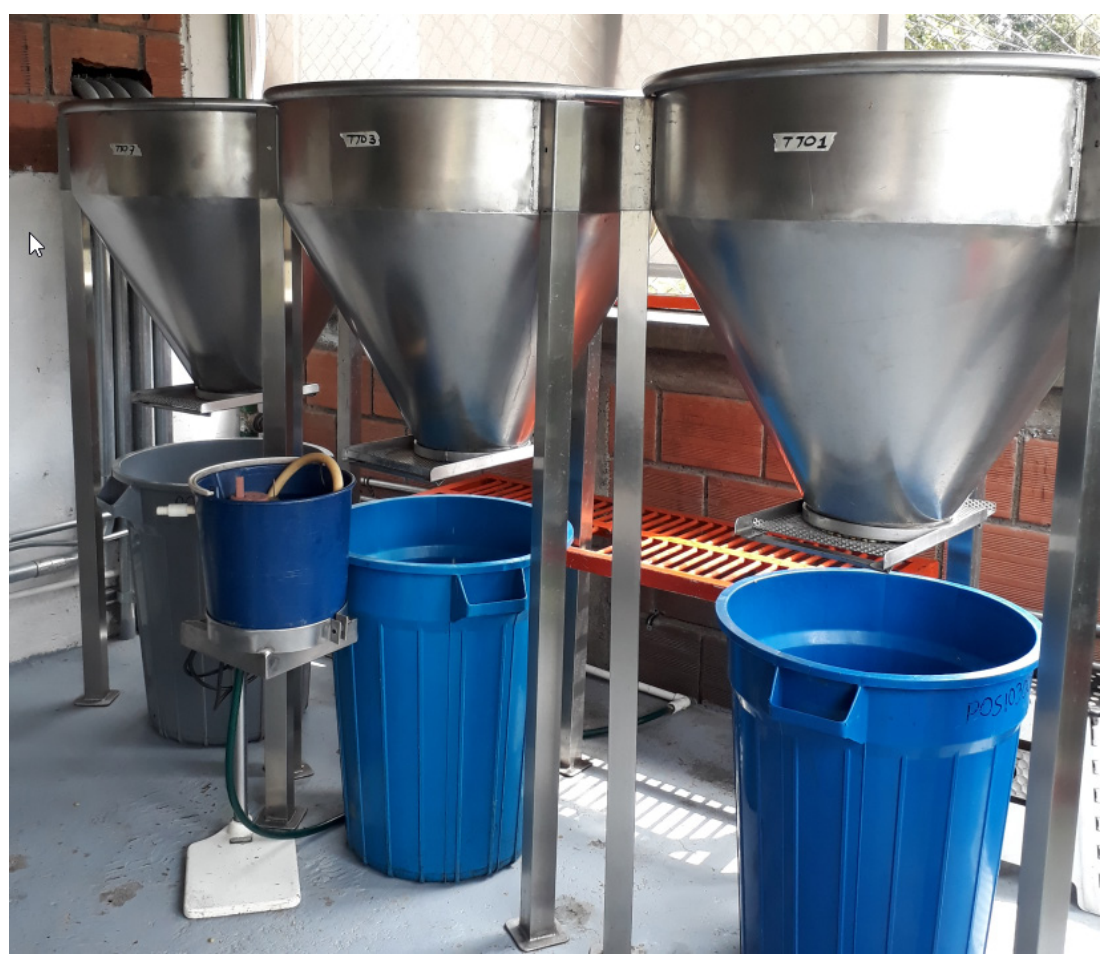

Figura 1. Montaje experimental con tanques de fermentación en acero inoxidable para la aplicación de tratamientos.

Los fluidos drenados de cada proceso, que contenían parte de la enzima aplicada y del mucílago degradado, fueron recolectados en la parte inferior de los tanques de fermentación (Figura 2), para determinar su volumen, $\mathrm{pH}$ y viscosidad. Los drenados de los tratamientos 1 y 4 fueron asperjados sobre las unidades de trabajo de café recién despulpado que conformaron los tratamientos 2 y 5 , respectivamente. Posteriormente los drenados de los tratamientos 2 y 5 se asperjaron al café despulpado en café de los tratamientos 3 y 6 , respectivamente. 


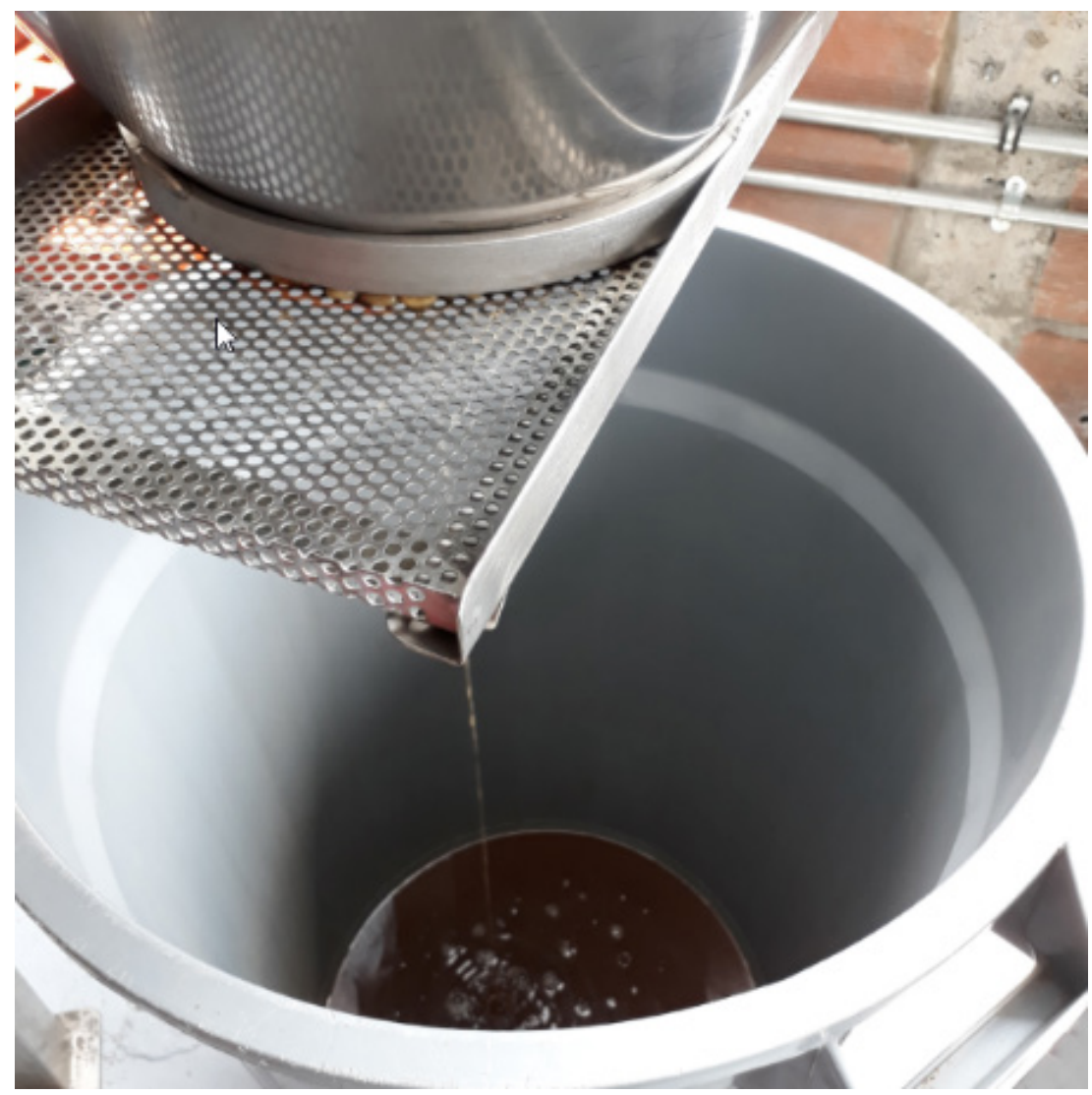

Figura 2. Recolección de los fluidos drenados de los procesos de remoción de mucílago.

\section{Evaluación de la acción de la enzima}

Para evaluar la acción de la enzima sobre la degradación de mucílago, se identificó el tiempo de cada tratamiento (variable de respuesta) utilizando el método Fermaestro ${ }^{\circledR}$. Este método permite identificar el momento en el que el café presenta un porcentaje de remoción de mucílago mayor al $95 \%$ mediante el cambio de densidad entre el café despulpado y el café con mucílago degradado, a partir del seguimiento de pérdida de volumen de una muestra del café recién despulpado, cuyo contenido inicial de mucílago debe ser en promedio del $25 \%$ (Peñuela et al., 2012).

Se registró el pH de la masa de café al inicio y al final de los tratamientos, con el fin de identificar estas características en el mucílago fresco y degradado respectivamente.

\section{Determinación de la calidad sensorial del café}

Las muestras de café pergamino seco fueron trilladas, tostadas, molidas y evaluadas por un panel conformado por cinco catadores Q-grader utilizando el protocolo de la Asociación de cafés Especiales, SCA por su sigla en inglés (SCAA, 2015). De este procedimiento se obtiene una calificación por atributos, diez en total, que componen la descripción organoléptica del café y que en sumatoria reportan el puntaje total, clasificando la calidad general del café en puntos SCA, que fue tomada también como variable de respuesta.

\section{Caracterización física de los fluidos drenados}

Para la medición de $\mathrm{pH}$ se utilizó un medidor de $\mathrm{pH}$ marca Handylab $\mathrm{pH} 11$, con un electrodo especial para fluidos viscosos (precisión 0,01). Los sólidos solubles totales fueron determinados por índice de refracción utili- 
zando un refractómetro digital marca Atago (precisión 0,1). Para la viscosidad se utilizó un viscosímetro marca Brookfield DVII (Precisión 0,01), con husillo Nro. 3 agitando a 60 rpm durante 90 segundos, previa calibración del equipo y estandarización del método, siguiendo el procedimiento recomendado por Hosseini et al. (2020).

\section{Análisis estadístico}

Se determinó el promedio y la variación (desviación estándar) para las variables de respuesta y las complementarias. Se aplicó el análisis de varianza con un nivel de confianza del $95 \%$ para las variables de respuesta (tiempo de remoción de mucílago y puntaje total), bajo el diseño experimental propuesto. Cuando se obtuvo diferencia significativa, se realizó la prueba de Tukey al 5 \%. Se utilizó el programa estadístico RStudio, Versión 1.1.423.

\section{RESULTADOS}

Según la caracterización de madurez de los bloques, el café utilizado para las pruebas presentó más del 74 \% en promedio de frutos en los estados maduros, en un rango entre 67,7 y $86,2 \%, 22 \%$ en promedio para frutos pintones, entre 10 y $33 \%$, y frutos verdes por debajo del 2,5\%, cumpliendo con los requisitos de madurez necesarios para el proceso de café. El análisis de varianza mostró que no hay efecto de los bloques (calidad de la materia prima), para el tiempo de remoción de mucílago $(p=0,3774)$, ni para la calidad sensorial $(p=0,987)$.

La evaluación de diferentes estados de madurez de frutos de café en variedades arábicas, no producen diferencias en la calidad sensorial (Velásquez et al., 2019)but variation in volatile and sensory characteristics over a range of maturities is not well studied. In this work, cherries from two coffee cultivars (Caturra, Catimor. Es posible obtener resultados similares en el tiempo de remoción de mucílago y la calidad del café con el uso de esta pectina liasa independiente de la composición de madurez del café a procesar, lo que representa una ventaja al momento de utilizar la enzima en campo, dadas las variaciones en los estados de madurez del café que se pueden presentar en diferentes épocas de cosecha.

\section{Tiempo de remoción de mucílago}

Se obtuvo una disminución del tiempo de proceso entre 22 y 85 \% respecto al testigo, en las dos concentraciones e independiente del número de ciclos de recirculación en nuevas tandas de café despulpado, mostrando efecto significativo de la interacción de estos dos factores $(p<0,0001)$. En el análisis de los factores separadamente, se presentó efecto de la concentración de la enzima con valores de tiempo significativamente diferentes $(p=0,0196)$, así como con en la recirculación de los fluidos drenados $(p<0,0001)$.

El menor tiempo de remoción de mucílago se obtuvo con la aplicación de la enzima original en razón de 100 mg de enzima por cada kilogramo de café despulpado. Con $50 \mathrm{mg} \cdot \mathrm{kg}^{-1} \mathrm{el}$ tiempo de proceso fue mayor en aproximadamente 1,5 horas respecto al tiempo obtenido para $100 \mathrm{mg} \cdot \mathrm{kg}^{-1}$ (Cuadro 2). Otros autores han reportado $6 \mathrm{~h}$ para eliminar el mucílago de café de variedades arábicas aplicando complejos enzimáticos compuestos por pectinasas y celulasas producidos con otros fines industriales (Puerta-Quintero, 2009; Menchu, 2019). Incluso tiempos de 24 horas aplicando pectina liasas de fuente bacteriana, como Bacillus tequilensis (Koshy \& De, 2019) y Bacillus subtilis (Oumer y Abate, 2017) las cuales presentaron máxima actividad a condiciones de $\mathrm{pH}$ alcalinos, que no son las condiciones de la fermentación en café. 
Cuadro 2.Tiempo de degradación de mucílago con la aplicación de la pectina liasa y recirculación de fluidos obtenidos .

\begin{tabular}{|c|c|c|c|c|}
\hline Tratamiento & $\begin{array}{c}\text { Tiempo } \\
\text { según Fermaestro®) } \\
\text { (horas) }\end{array}$ & D.E. & $\begin{array}{c}\text { Diferencia de tiempo } \\
\text { con el primer uso } \\
\text { (horas) }\end{array}$ & $\begin{array}{c}\text { Diferencia de tiempo } \\
\text { con el testigo } \\
\text { (horas) }\end{array}$ \\
\hline 1 & $4,31 \mathrm{~d}$ & 0,36 & --- & 15,89 \\
\hline 2 & $15,53 \mathrm{~b}$ & 0,59 & 11,23 & 4,66 \\
\hline 3 & $5,58 \mathrm{c}$ & 0,75 & 1,27 & 14,62 \\
\hline 4 & $2,93 \mathrm{e}$ & 0,50 & --- & 17,27 \\
\hline 5 & $15,83 \mathrm{~b}$ & 0,50 & 12,91 & 4,36 \\
\hline 6 & $5,51 \mathrm{c}$ & 0,80 & 2,59 & 14,68 \\
\hline 7 & $20,19 \mathrm{a}$ & 1,07 & --- & -- \\
\hline
\end{tabular}

Letras diferentes para la variable tiempo según Fermaestro ${ }^{\circledR}$ indican diferencia significativa según prueba de Tukey al $5 \%$. D.E. Desviación Estándar

Con la recolección de los fluidos drenados de los tratamientos 1 y 4, para hacer la recirculación sobre nuevas tandas de café despulpado (tratamientos 2 y 5), se observó un incremento en el tiempo de remoción a más de 15 horas, independiente de la concentración de enzima empleada, que pudo estar relacionado con retención de la mayor parte de la enzima por el mucílago adherido al grano. JØrgensen y Pinelo (2017) explican cómo la recirculación de enzimas contenida en el residuo líquido, es el método técnicamente más simple, dado el aprovechamiento de la separación sólido-líquido propia del proceso, sin embargo, se ha demostrado que gran parte de la enzima permanece absorbida en la parte sólida, como es el caso de la hidrólisis de cascarilla de trigo, cuyo rendimiento fue el $90 \%$ de la hidrólisis inicial, después de dos ciclos y $75 \%$ después del tercer ciclo según Qi et al., 2011, citado por JØrgensen y Pinelo (2017).

Para los tratamientos 3 y 6, se observó una disminución del tiempo de remoción respecto a los tratamientos anteriores ( 2 y 5), ya que los fluidos drenados de este segundo uso tienen un tiempo de al menos 15 horas, en el que se presenta un proceso similar a la fermentación natural, con el crecimiento microbiano y la producción de enzimas degradadoras de mucílago.

Como ha sido ampliamente documentado, durante la fermentación natural en café se producen diferentes tipos de pectinasas, que además de pectina liasa incluyen poligalacturonasas, protopectinasas y pectinestearasas, dada la presencia y crecimiento de microorganismos con gran capacidad pectinolítica (Oumer \& Abate, 2018; Patidar et al., 2018; Haile \& Kang, 2019; Koshy \& De, 2019). La presencia de estas enzimas en los fluidos drenados que fueron utilizados en 2 y 5 , redujeron el tiempo de remoción para los tratamientos 3 y 6 , respecto a los anteriores.

Respecto a los cambios en la acidez de la masa (Cuadro 3), los valores iniciales de $\mathrm{pH}$ indicaron diferencias descriptivas en todos los tratamientos, que se relacionaron con el tiempo de espera en fruto antes del despulpado, en el que se presentó una leve disminución del pH, indicando acidificación de la masa, sin embargo, no se presentó degradación de mucílago, debido a que el contenido inicial se mantuvo en promedio en $25 \%$, requerido para el funcionamiento del método Fermaestro ${ }^{\circledR}$ (Peñuela et al., 2012). Cada tratamiento inició una vez el anterior finalizó con la misma masa de café recolectado (bloque), siendo más notorio este cambio para los tratamientos 3 y 6, cuyas fermentaciones anteriores ( 2 y 5) tuvieron entre 15 y 16 horas en el proceso. En este caso se presentó producción de ácidos al interior del fruto, indicando actividad metabólica de los microorganismos presentes que se relacionaron con la disminución de pH, comportamiento observado por Peñuela-Martínez et al. (2018). Se debe considerar que, la pectina liasa adicionada, presenta una actividad máxima cercana a $\mathrm{pH} 5,0$ y es poco estable a cambios de $\mathrm{pH}$. La estabilidad de las enzimas a diferentes valores de $\mathrm{pH}$ es determinante para las aplicaciones industriales, ya que tienen efectos sobre su actividad, un pequeño cambio de $\mathrm{pH}$ produce una disminución drástica de su actividad (Ahmed y Sohail 2020). Para cepas de Aspergillus Niger estos valores están entre 4,2 y 6,5 (Menchu, 2019; Kharazmi et al., 2020; Mohammadia et al., 2020). Las pectina liasas fúngicas generalmente presentan una actividad óptima en condiciones ácidas o neutras (Xu et al., 2015; De Oliveira et al., 2018; He et al., 2018; Kc et al., 2020). La disminución del pH entre el inicio y final de los tratamientos fue más notoria para aque- 
Ilos que presentaron mayor tiempo de remoción y el testigo, con valores que estuvieron entre los reportados para este tipo de proceso (Avallone et al., 2000; Peñuela et al., 2010; Córdoba \& Guerrero 2016).

Cuadro 3. Valores promedio para el $\mathrm{pH}$ al inicio y al final de los tratamientos.

\begin{tabular}{|c|c|c|}
\hline \multirow{2}{*}{ Tratamiento } & \multicolumn{2}{|c|}{$\mathbf{p H}$} \\
\cline { 2 - 3 } & Inicial & Final \\
\hline 1 & 5,6 & 5,3 \\
\hline 2 & 5,4 & 3,9 \\
\hline 3 & 4,8 & 4,5 \\
\hline 4 & 5,5 & 5,3 \\
\hline 5 & 5,5 & 3,8 \\
\hline 6 & 4,9 & 4,6 \\
\hline 7 & 5,5 & 3,5 \\
\hline
\end{tabular}

\section{Calidad sensorial}

El análisis de varianza, no mostró efecto de la aplicación de los tratamientos respecto a la calidad sensorial del café, ni para la interacción ( $p=0,687)$, ni para los factores concentración $(p=0,179)$ y el ciclo de recirculación $(p=0,637)$ por separado. La calidad general, definida como el puntaje total SCA (Cuadro 4), estuvo cercana a 81 puntos independiente de las variaciones aplicadas en los tratamientos, que además clasificó el café como especial (SCAA, 2015), representando el café suave lavado por el que es reconocido el café colombiano en el mercado internacional. Se presenta ademá los promedios y variación de los puntajes obtenidos para los principales atributos del café, como fragancia/aroma, sabor y acidez, que no fueron afectados de manera particular por los tratamientos aplicados.

La pectina liasa adicionada al café, se caracteriza por degradar la pectina, sin alterar el grupo éster de su estructura lo que es importante para el aroma (Xu et al., 2015), siendo este uno de los atributos sensoriales más importantes para el café. Además, este tipo de pectinasa se ha identificado como una de las enzimas que mayor actividad presenta en la degradación del mucílago, debido a que es producida por varios de los microorganismos que participan en la fermentación (De Melo Pereira et al., 2019; Haile \& Kang, 2019; Da Mota et al., 2020). Adicionalmente, la actividad pectinolítica es uno de los criterios considerados para la selección de microorganismos que pueden ser utilizados como cultivos iniciadores, para ser usados en la fermentación en café con el fin de mejorar el proceso o la calidad sensorial (Siridevi et al., 2019; Haile \& Kang, 2019).

Cuadro 4. Resultados del análisis sensorial, en puntos SCA, de las muestras de café de los tratamientos.

\begin{tabular}{|c|c|c|c|c|c|c|c|c|}
\hline Tratamiento & Promedio Taza & D.E. & Fragancia/aroma & D.E. & Sabor & D.E. & Acidez & D.E. \\
\hline 1 & 81,50 & 1,17 & 7,51 & 0,21 & 7,51 & 0,21 & 7,38 & 0,19 \\
\hline 2 & 81,32 & 0,96 & 7,43 & 0,21 & 7,43 & 0,21 & 7,36 & 0,19 \\
\hline 3 & 81,80 & 1,00 & 7,58 & 0,16 & 7,58 & 0,16 & 7,45 & 0,20 \\
\hline 4 & 81,18 & 1,41 & 7,44 & 0,17 & 7,44 & 0,17 & 7,34 & 0,24 \\
\hline 5 & 81,66 & 1,28 & 7,50 & 0,17 & 7,50 & 0,17 & 7,45 & 0,23 \\
\hline 6 & 81,73 & 1,07 & 7,53 & 0,22 & 7,53 & 0,22 & 7,43 & 0,19 \\
\hline 7 & 81,36 & 0,57 & 7,45 & 0,09 & 7,45 & 0,09 & 7,38 & 0,13 \\
\hline
\end{tabular}

D.E. Desviación Estándar

\section{Características de los fluidos drenados}

Las principales características de los fluidos drenados utilizados para las aplicaciones de los tratamientos (Cuadro 5), se determinaron con el fin de asociar la actividad de la enzima utilizada. 
Los valores de $\mathrm{pH}$ de los fluidos drenados fueron mayores que los registrados en la masa de café, sin embargo, se relacionan con el comportamiento de la acidificación observado durante los tratamientos. El rango de valores del pH de los fluidos evaluados estuvo entre 3,8 y 5,6, característico del comportamiento de los efluentes del lavado del café. Esta acidificación es propia del proceso de degradación del mucílago de café, siendo los desechos orgánicos generados por la fermentación los que aumentan las características ácidas del agua del lavado (Dadi et al., 2018).

El Cuadro 5 muestra también el valor medio del volumen de fluidos drenados recolectados en el tratamiento testigo, que fue menor al obtenido en los demás tratamientos, en los que se observó disminución del volumen a mayor recirculación sobre nuevas tandas de café, comportamiento que fue común para las dos concentraciones de enzima evaluadas. Los valores de viscosidad determinados presentaron una relación inversa con el volumen de fluidos recolectados, a mayor viscosidad menor contenido de fluidos drenados, que se puede asociar a una mayor resistencia para que el fluido pase por los intersticios entre los granos, dificultando el drenaje de los mismos. La aplicación de la enzima original generó una reducción de la viscosidad entre el 29,6 y 38,8 \% dependiendo de la concentración utilizada, respecto a la viscosidad obtenida para el testigo. El contacto de la pectinasa con la pectina hace que el sustrato disminuya su capacidad de retener agua, causando su liberación. Comportamiento y valores similares de reducción de viscosidad fueron obtenidos por De Oliveira et al. (2018), para la clarificación de jugo de manzana aplicando una pectinasa inmovilizada de Aspergillus aculeatus con reducción de viscosidad entre 20,8 y $26 \%$.

Los fluidos de los tratamientos 1 y 4, presentaron los menores valores de viscosidad indicando una mayor actividad de la enzima, dado que la disminución de la viscosidad de una solución es inversamente proporcional a la cantidad de enzima aplicada, por lo que puede ser considerada como un método para medir la actividad enzimática de las soluciones (Patidar et al., 2018).

Cuadro 5. Valores promedio para el volumen de drenados, $\mathrm{pH}$ y sólidos solubles totales para los drenados de los tratamientos.

\begin{tabular}{|c|c|c|c|c|c|c|c|c|}
\hline TTO & $\begin{array}{c}\text { Volumen } \\
(\mathbf{m L})\end{array}$ & $\begin{array}{c}\text { D. E. } \\
(\mathbf{m L})\end{array}$ & $\mathrm{pH}$ & D. E. & $\begin{array}{c}\text { SST } \\
\left({ }^{\circ} \mathrm{Bx}\right)\end{array}$ & $\begin{array}{c}\text { D. E. } \\
\left({ }^{\circ} \mathrm{Bx}\right)\end{array}$ & $\begin{array}{c}\text { Viscosidad } \\
(\mathrm{cP})\end{array}$ & $\begin{array}{c}\text { D. E. } \\
(\mathbf{c P})\end{array}$ \\
\hline 1 & $2.894,5$ & 686,0 & 5,26 & 0,10 & 16,3 & 2,0 & 6,9 & 1,8 \\
\hline 2 & $2.335,0$ & 865,6 & 4,67 & 0,18 & 16,6 & 1,6 & 22,3 & 5,7 \\
\hline 3 & $1.893,0$ & 661,9 & 4,37 & 0,37 & 15,7 & 1,9 & 47,0 & 17,7 \\
\hline 4 & $2.630,0$ & 553,7 & 5,52 & 0,13 & 16,6 & 1,1 & 6,0 & 2,0 \\
\hline 5 & $2.494,0$ & 894,4 & 4,76 & 0,14 & 16,7 & 1,3 & 19,8 & 8,4 \\
\hline 6 & $2.068,5$ & 626,3 & 4,41 & 0,33 & 15,6 & 1,6 & 30,9 & 7,3 \\
\hline 7 & $1.875,5$ & 595,6 & 4,44 & 0,12 & 18,1 & 1,7 & 9,8 & 4,0 \\
\hline
\end{tabular}

D.E. Desviación estándar

\section{CONCLUSIONES}

Las variables tiempo de remoción de mucílago y calidad sensorial del café obtenido de los tratamientos no fueron influenciadas por la variación en la madurez de los frutos que fueron procesados, lo que se convierte en una ventaja para el proceso cuando se utiliza la enzima, dadas las variaciones en madurez que se pueden presentar en los diferentes tiempos de cosecha o entre épocas de cosecha del café.

Se corroboró el tiempo de tres horas para remover el mucílago de café utilizando una concentración de la enzima de 100 mg.kg-1 ${ }^{-1}$ resultado de la investigación realizada por (Peñuela-Martínez et al., 2010). Además, se identificó que al utilizar la mitad de la concentración anterior se obtiene un aumento del $50 \%$ del tiempo, que representan una reducción del $79 \%$, respecto al testigo. Lo anterior indica que es posible utilizar $50 \mathrm{mg}^{\mathrm{kg}}{ }^{-1}$ para remover el mucílago del café en corto tiempo. La decisión de la concentración a utilizar dependerá del ahorro en el tiempo de proceso que se quiera obtener finalmente. 
La recolección de los fluidos drenados del proceso y la recirculación de la enzima contenida en los mismos sobre una nueva tanda de café despulpado, resulta en una práctica con poca ganancia en el tiempo, ya que el aumento está entre 3,6 y 5,4 veces más que aplicación de la enzima original. Lo anterior, no representa una ventaja en términos de menor tiempo de proceso, sobre todo en época de cosecha, incluso teniendo en cuenta las bajas concentraciones de producto necesario para asistir la degradación del mucílago. Se debe considerar que, soportado en la hidrólisis enzimática de otros procesos industriales, la mayor cantidad de enzima con actividad remanente permanece en la parte sólida del proceso, para este caso en la superficie de los granos con mucílago degradado, cuya aplicación práctica se dificulta por el volumen de los tanques que contienen el café para la degradación.

La determinación de las variables como volumen de fluidos drenados, sólidos solubles y la viscosidad de los mismos, guardaron relación con la actividad de la enzima, debido a que a medida que se hizo la recirculación de los mismos, se presentó una disminución en el volumen recolectado y de sólidos solubles y un aumento en la viscosidad, indicando la pérdida de actividad enzimática que influyó en el tiempo de remoción de mucílago de cada tratamiento.

\section{AGRADECIMIENTOS}

Este trabajo fue financiado por el Centro Nacional de Investigaciones de Café - Cenicafé, de la Federación Nacional de Cafeteros de Colombia. Se agradece especialmente al Dr. Rubén Medina líder de la Disciplina de Biometría de Cenicafé, por su asesoría en la formulación metodológica del proyecto de investigación.

\section{REFERENCIAS}

AHMED, ASIA; SOHAIL, MUHAMMAD. Characterization of pectinase from Geotrichum candidum AA15 and its potential application in orange juice clarification. Journal of King Saud University - Science, v. 32, n. 1, 2020, p. 955-961. https://doi.org/10.1016/j.jksus.2019.07.002

ASGARI, K.; LABBAFI, M.; KHODAIYAN, F.; KAZEMI, M.; HOSSEINI, S. High-methylated pectin from walnut processing wastes as a potential resource: Ultrasound assisted extraction and physicochemical, structural and functional analysis. Elsevier, International Journal of Biological Macromolecules, v. 152, 2020, p. 1274-1282.

https://doi.org/10.1016/j.ijbiomac.2019.10.224

AVALLONE, S.; GUIRAUD, J.P.; GUYOT, B.; OLGUIN, E.; BRILLOUET, J.M. Polysaccharide Constituents of CoffeeBean Mucilage. Journal of Food Science, v. 65, n. 8, 2000, p. 1308-1311. https://doi.org/10.1111/j.1365-2621.2000.tb10602.x

CÓRDOBA-CASTRO, NANCY-MARLENY; GUERRERO-FAJARDO, JESÚS-ESTEBAN. Caracterización de los procesos tradicionales de fermentación de café en el departamento de Nariño. Biotecnología En El Sector Agropecuario Y Agroindustrial, v. 14, n. 2, 2016, p. 75-83. https://revistas.unicauca.edu.co/index.php/biotecnologia/article/view/1675/622

DADI, DESSALEGN; MENGISTIE, EMBIALLE;TEREFE, GUDINA; GETAHUN, TADESSE; HADDIS, ALEMAYEHU; BIRKE, WONDWOSSEN; BEYENE, ABEBE; LUIS, PATRICIA; VAN DER BRUGGEN, BART. Assessment of the effluent quality of wet coffee processing wastewater and its influence on downstream water quality Ecohydrol. Hydrobiology, v. 18, n. 2, 2018, p. 201-211.

https://doi.org/10.1016/j.ecohyd.2017.10.007

DA MOTA, MARCELA-CAROLINE; BATISTA, NÁDIA-NARA; RABELO-SANCES, MARIANE-HELENA; RIBEIRO, DIEGO-EGIDIO; BORÉM, FLÁVIO-MEIRA; SCHWAN, ROSANE-FREITAS. Influence of fermentation conditions on the sensorial quality of coffee inoculated with yeast. Food Research International, v. 136, 2020, e109482.

https://doi.org/10.1016/j.foodres.2020.109482 
DE MELO-PEREIRA, GILBERTO; DE CARVALHO-NETO, DÃO P.; MAGALHÃES-JÚNIOR, ANTONIO I.; VÁSQUEZ-ZULMA, S.; MEDEIROS, ADRIANE B.P.; VANDENBERGHE, LUCIANA P.S.; SOCCOL, CARLOS R. Exploring the impacts of postharvest processing on the aroma formation of coffee beans - A review. Food Chemistry, v. 272, 2019, p. 441-452. https://doi.org/10.1016/j.foodchem.2018.08.061

DE OLIVEIRA-LIRA, RODRIGO; LOPES-DIAS, JÔNATAS; SOARES-DA SILVA, OSMAR; SOUZA-PORTO, TATIANA. Immobilization of pectinase from Aspergillus aculeatus in alginate beads and clarification of apple and umbu juices in a packed bed reactor. Food and Bioproducts Processing v. 109, 2018, p. 9-18. https://doi.org/10.1016/j.fbp.2018.02.005

HAILE, MESFIN; KANG, W.H. Isolation, Identification, and Characterization of Pectinolytic Yeasts for Starter Culture in Coffee Fermentation. Microorganisms, v. 7, n. 10, 2019 , e7100401. https://doi.org/10.3390/microorganisms7100401

HE, YULAN; PAN, LI; WANG, BIN. Efficient Over-expression and Application of High-performance Pectin Lyase by Screening Aspergillus niger Pectin Lyase Gene Family. Biotechnology and Bioprocess Engineering, v. 23, n. 6, 2018, p. 662-669. https://doi.org/10.1007/s12257-018-0387-1

HOSSEINI, SEYED-SAEID; KHODAIYAN, FARAMARZ; MOUSAVI-SEYED, MOHAMMAD E.; AZIMI, SEYEDEHZAHRA; GHARAGHANI, MOHAMMAD. Immobilization of pectinase on the glass bead using polyaldehyde kefiran as a new safe cross-linker and its effect on the activity and kinetic parameters. Food Chemistry, v. 309, 2020, e125777. https://doi.org/10.1016/j.foodchem.2019.125777

JOHN, JULIANA; KAIMAL-SURENDRANATHAN, K.K.; SMITH, MATTHEW L.; RAHMAN, PATTANATHU K.S.M; VELAYUDHAPERUMAL-CHELLAM, PADMANABAN. Advances in upstream and downstream strategies of pectinase bioprocessing: A review, International. Journal of Biological Macromolecules, v. 162, 2020, p. 1086-1099. https://doi.org/10.1016/j.ijbiomac.2020.06.224

JØRGENSEN, HENNING; PINELO, MANUEL. Enzyme recycling in lignocellulosic biorefineries. Biofuels, Bioproducts and Biorefining journal, v. 11, 2017, p. 150-167. https://doi.org/10.1002/bbb.1724

KAZEMI, MILAD; KHODAIYAN, FARAMARZ; LABBAFI, MOHSEN; HOSSEINI, SEYED-SAEID; HOJJATI, MOHAMMAD. Pistachio green hull pectin: Optimization of microwave-assisted extraction and evaluation of its physicochemical, structural and functional properties. Food Chemistry, v. 271, 2019, p. 663-672. https://doi.org/10.1016/j.foodchem.2018.07.212

KC, SUDEEP; UPADHYAYA, JITENDRA; JOSHI-DEV, RAJ; LEKHAK, BINOD; CHAUDHARY-KUMAR, DHIRAJ; PANT-RAJ, BHOJ; BAJGAI-RAJ, TIRTHA; DHITAL, RAJIV; KHANAL, SANTOSH; NIRANJAN, KOIRALA; RAGHAVAN, VIJAYA. Production, Characterization, and Industrial Application of Pectinase Enzyme Isolated from Fungal Strains. Fermentation, v. 6, n. 59, 2020, p. 1 - 10. https://doi.org/10.3390/fermentation6020059

KHARAZMI, SARA; TAHERI-KAFRANI, ASGHAR; SOOZANIPOUR, ASIEH. Efficient immobilization of pectinase on trichlorotriazine-functionalized polyethylene glycol-grafted magnetic nanoparticles: A stable and robust nanobiocatalyst for fruit juice clarification. Food Chemistry, v. 325, 2020, e126890. https://doi.org/10.1016/j.foodchem.2020.126890

KOSHY, MITTU; DE, SALAMUN. Effect of Bacillus tequilensis SALBT crude extract with pectinase activity on demucilation of coffee beans and juice clarification. Journal of Basic Microbiology, v. 59, n. 12, 2019, p. 1185-1194. https://doi.org/10.1002/jobm.201900321

MENCHÚ-ÁLVAREZ, CARLOS-MAURICIO. Evaluación de la remoción del mucílago de café asistido enzimáticamente y sus efectos en el presecado del grano en pergamino [Tesis Ingeniería Química]. Guatemala (Guatemala): Universidad de San Carlos de Guatemala, Facultad de Ingeniería, Escuela de Ingeniería Química, 2019, 80 p.

http://www.repositorio.usac.edu.gt/13998/1/Carlos\%20Mauricio\%20Mench\%C3\%BA\%20Alvarez.pdf 
MOHAMMADIA, MARYAM; REZAEI-MOKARRAMA, REZA; SHAHVALIZADEHB, RAHIM; SARABANDIC, KHASHAYAR; LIMD, LOONG-TAK; HAMISHEHKARE, HAMED. Immobilization and stabilization of pectinase on an activated montmorillonite support and its application in pineapple juice clarification, Food Bioscience, v. 36, 2020, e100625. https://doi.org/10.1016/j.fbio.2020.100625

OUMER, OLIYAD-JEILU; ABATE, DAWIT. Screening and molecular identification of pectinase producing microbes from coffee pulp. BioMed research international, v. 2018, 2018, e2961767. https://doi.org/10.1155/2018/2961767

PATIDAR-KUMAR, MUKESH; NIGHOJKAR, SADHANA; KUMAR, ANIL; NIGHOJKAR, ANAND. Pectinolytic enzymes-solid state fermentation, assay methods and applications in fruit juice industries: a review. 3 Biotech, v. 8, n. 4, 2018, p.1 - 24. https://doi.org/10.1007/s13205-018-1220-4

PEÑUELA-MARTÍNEZ, AIDA-ESTHER; PABÓN-USAQUÉN, JENNY; RODRÍGUEZ-VALENCIA, NELSON; OLIVEROS-TASCÓN, CARLOS-EUGENIO. Evaluación de una enzima pectinolítica para el desmucilaginado del café. Cenicafé, v. 61 n. 3, 2010, p. 241-250. https://www.cenicafe.org/es/publications/arc061\%2803\%29241-251.pdf

PEÑUELA-MARTÍNEZ, AIDA-ESTHER; SANZ-URIBE, JUAN-RODRIGO; PABÓN-USAQUÉN, JENNY-PAOLA. Método para identificar el momento final de la fermentación de mucílago de café. Cenicafé, v. 63, n. 1, 2012, p. 120-131. https://www.cenicafe.org/es/publications/Revista63_1.pdf

PEÑUELA-MARTÍNEZ, AIDA-ESTHER; ZAPATA-ZAPATA, ARLEY-DAVID; DURANGO, RESTREPO, DIEGOLUIS. Performance of different fermentation methods and the effect on coffee quality (Coffea Arabica L.). Coffee Science, v. 13, n. 4, 2018, p. 465-476. https://doi.org/10.25186/cs.v13i4.1486

PUERTA-QUINTERO, GLORIA-INÉS. Efecto de enzimas pectolíticas en la remoción del mucílago de /Coffea arábica/ L. según el desarrollo del fruto. Cenicafé, v. 60, n. 4, 2009, p. 291-312. https://www.cenicafe.org/es/publications/arc060\%2804\%29291-312.pdf

RAMDAS-SHET, ANIL; VIJAYKUMAR-DESAI, SHIVALINGASARGA; ACHAPPA, SHARANAPPA. Pectinolytic enzymes: classification, production, purification and applications. Research Journal of Life Sciences, Bioinformatics, Pharmaceutical and Chemical Sciences, RJLBPCS, v. 4, n. 3, 2018, p. 337 - 349. http://www.rjlbpcs.com/article-pdf-downloads/2018/19/261.pdf

SALVADOR-PINOS, CARMEN A.; MESA-NOVAL, ADALIS; MESA-GARRIGA, LAYANIS; GONZÁLEZ-SUÁREZ, ERENIO. Recycling Of Commercial Enzymes In The Production Of Second Generation Ethanol. Centro Azúcar, v. 45, n. 3, 2018, p. 78-90. https://biblat.unam.mx/hevila/Centroazucar/2018/no3/8.pdf

SANZ-URIBE, JUAN-RODRIGO; YUSIANTO; MENON, SUNALINI N.; PEÑUELA-MARTINEZ, AIDA-ESTHER; OLIVEROS-TASCON, CARLOS-EUGENIO; HUSSON, JWANRO; BRANDO, CARLOS; RODRIGUEZ, ALEXIS. Postharvest processing: Revealing the green bean. The craft and science of coffee. En: FOLMER, B. Amsterdam (Netherland): Academic press, 2017, p. 51-79, ISBN 978-0-12-803520-7. https://doi.org/10.1016/B978-0-12-803520-7.00003-7

SPECIALTY COFFEE ASSOCIATION (SCA). SCA Protocols | Cupping Specialty Coffee. 2015 http://www.scaa.org/?page=resourcesyd=cupping-protocols [Consultado julio 30 de 2020].

SIRIDEVI, G.B.; DEVENDRA-HAVARE, BASAVARAJ K.; PUSHPA S., MURTHY. Coffee starter microbiome and in-silico approach to improve Arabica coffee. LWT Food Science and Technology, v. 114, 2019, e108382. https://doi.org/10.1016/j.Iwt.2019.108382

TIBADUIZA-VIANCHÁ, CARLOS-ALFONSO; RAMÍREZ-GÓMEZ, CÉSAR-AUGUSTO; SANZ-URIBE, JUANRODRIGO; OLIVEROS-TASCÓN, CARLOS-EUGENIO. Análisis y diseño de beneficiaderos ecológicos comunitarios para café proyecto Manos al agua. 1 ed. Manizales (Colombia): Cenicafé, 2018, 105 p, ISBN: 978-958-8490-33-5. 
VELÁSQUEZ, SEBASTIÁN; PEÑA, NESTOR; BOHÓRQUEZ, JUAN-CARLOS; GUTIERREZ, NELSON; SACKS, GAVIN L. Volatile and sensory characterization of roast coffees - Effects of cherry maturity. Food Chemistry, v. 274, 2019, p. 137-145.

https://doi.org/10.1016/j.foodchem.2018.08.127

XU, S.X.; QIN, X.; LIU, B.; ZHANG, D.Q.; ZHANG, W.; WU, K.; ZHANG, Y.H. An acidic pectin lyase from Aspergillus niger with favourable efficiency in fruit juice clarification. Letters in Applied Microbiology, v. 60, n. 2, 2015, p. 181-187. https://doi.org/10.1111/lam.12357

XUE, YING; JAMEEL, HASAN; PARK, SUNKYU. Strategies To Recycle Enzymes And Their Impact On Enzymatic Hydrolysis For Bioethanol Production. Bioresurces, v. 7, n. 1, 2012, p. 602-615. https://bioresources.cnr.ncsu.edu/wp-content/uploads/2016/06/BioRes_07_1_0602_Xue_JP_Strat_Recycl_Enzymes_Bioethanol_Prodn_2328.pdf

YUAN, YE; RUI, ZHAI; LI, YING; CHEN, XIANGXUE; JIN, MINGJIE. Developing fast enzyme recycling strategy through elucidating enzyme adsorption kinetics on alkali and acid pretreated corn stover. Biotechnology for Biofuels, v.11, n. 316, 2018. https://doi.org/10.1186/s13068-018-1315-5

ZEUNER, BIRGITTE; THOMSEN, THORE-BACH; STRINGER, MARY-ANN; KROGH, KRISTIAN B.R.M; MEYER ANNE S.; HOLCK, JESPE. Comparative Characterization of Aspergillus Pectin Lyases by Discriminative Substrate Degradation Profiling. Bioengineering Biotechnology, vol. 8, 2020, p. 873. https://doi.org/10.3389/fbioe.2020.00873 